\title{
GT2015-43055
}

\section{APPLICATION OF PINNIPED VIBRISSAE TO AEROPROPULSION}

\author{
Vikram Shyam \\ NASA Glenn Research Center \\ Cleveland, OH, USA
}

\author{
Douglas Thurman \\ US Army Research Laboratory \\ Cleveland, $\mathrm{OH}$, USA
}

\author{
Ali Ameri \\ The Ohio State University \\ Columbus, $\mathrm{OH}$, USA
}

\author{
Adam Wroblewski \\ NASA Glenn Research Center \\ Cleveland, $\mathrm{OH}, \mathrm{USA}$
}

\author{
Philip Poinsatte \\ NASA Glenn Research Center \\ Cleveland, $\mathrm{OH}$, USA \\ Christopher Snyder \\ NASA Glenn Research Center \\ Cleveland, OH, USA
}

\begin{abstract}
Vibrissae (whiskers) of Phoca Vitulina (Harbor Seal) and Mirounga Angustirostris (Elephant Seal) possess undulations along their length. Harbor Seal Vibrissae have been shown to reduce vortex induced vibrations and reduce drag compared to appropriately scaled cylinders and ellipses. Samples of Harbor Seal vibrissae, Elephant Seal vibrissae and California Sea Lion vibrissae were collected from the Marine Mammal Center in California. CT scanning, microscopy and 3D scanning techniques were utilized to characterize the whiskers. Leading edge parameters from the whiskers were used to create a 3D profile based on a modern power turbine blade. The NASA SW2 cascade wind tunnel facility was used to perform hotwire surveys and pitot surveys in the wake of the 'Seal Blades' to provide validation of Computational Fluid Dynamics simulations. Computational Fluid Dynamics simulations were used to study the effect of incidence angles from -37 to +10 degrees on the aerodynamic performance of the Seal blade. The tests and simulations were conducted at a Reynolds number of 100,000 based on inlet conditions and blade axial chord. The Seal blades showed consistent performance improvements over the baseline configuration. It was determined that a fuel burn reduction of approximately $5 \%$ could be achieved for a fixed wing aircraft.
\end{abstract}

\section{INTRODUCTION}

A key challenge for variable speed power turbines is to maintain high turbine efficiency over main rotor speed variations from $54 \%$ to $100 \%$ [1, 2]. Power turbines must therefore operate at a large range of incidences (60 degrees or greater,) and in low Reynolds number regimes. For fixed wing aircraft, current low pressure turbine (LPT) designs are unable to maintain aerodynamic performance at altitude cruise conditions where the Reynolds number has dropped substantially from the sea level value [3]. Currently, boundary layer separation at low Reynolds number is either accepted, or the blading is designed for reduced loading to avoid the issue but penalizes the engine with additional LPT weight (and possibly reduced Sea Level Static performance). Secondary flows and leakage flows are a major source of loss. The loss can be assessed by measuring the total pressure loss coefficient in the wake.

LPT efficiency is known from system studies to have the strongest impact on engine specific fuel consumption reduction and is the heaviest component in the engine. Hollow LPT blades have been envisioned as a way to reduce engine weight. Reducing blade weight as well as reducing the cruise performance loss would doubly benefit future engine designs which are attempting to reduce weight by increasing the per stage work and thereby reducing stage count. Additional areas of improvement for the gas turbine and for propulsors in general are the fan blades for fixed wing aircraft or rotors and tails for rotorcraft.

As part of the ideation process to develop a blade geometry that could simultaneously benefit aerodynamic and acoustic performance a comprehensive literature review of biomimetic aerodynamic and acoustic applications was conducted. The review covered owls, harbor seals, whales, sharks, sailfish, dragonflies, cacti and palm trees. Grooves and ribs on blades have been extensively investigated and found to be beneficial in drag reduction under certain conditions [4-6]. For the trailing edge, chevrons and other forms of serrations have been attempted on fan blades but these are sensitive to local flow conditions. Halasz [7] investigated the use of steady trailing edge

This material is declared a work of the U.S. Government and is not subject to copyright protection in the United States.

Approved for public release. Distribution is unlimited. 
blowing for fan blades by unevenly distributing the ejection slots among the fan blades of a rotor/stator configuration. Figure 1 shows the sources of noise from a turbofan engine [7]. The fan noise and noise from the aft turbine components are the dominant sources that contribute to noise that is considered undesirable to humans. Halasz [7] found that the uneven distribution changed the spectral shape of the wake.

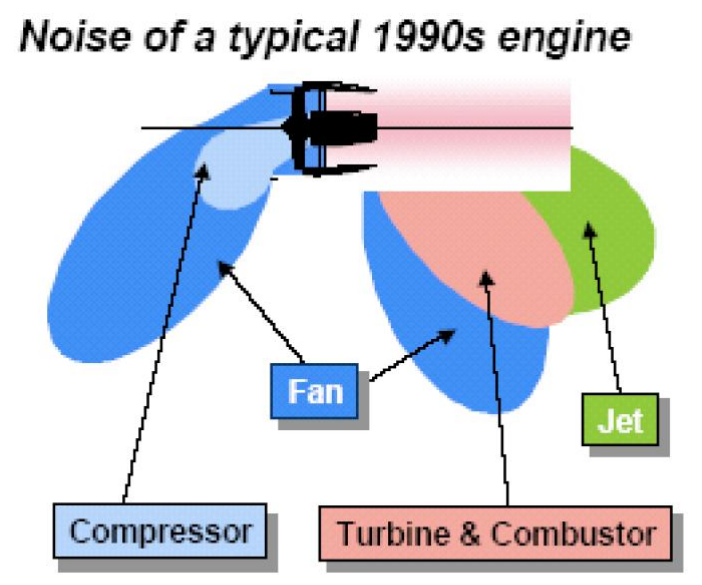

Figure 1.3: Turbofan Engine Noise Sources.

\section{Figure 1. Noise sources from a turbofan engine. [7]}

For external flow, whale tubercles [8-13] inspired wind turbine blades have had great success. These blades use the bumps on the leading edge to delay stall. The creation of downstream vorticity due to the channeling of flow between tubercles could also be detrimental to downstream components. Also, no reduction in drag is found at zero incidence. Similar conclusions are drawn for studies using sinusoidal leading edges [14]. In nature, dragonfly wings have serrations to mitigate separation at low Reynolds numbers [15-17]. For application to the low pressure turbine, one must ensure that the flow is laminar for this modification to work and the scale of serrations on the blade must be on the order of magnitude of blade thickness. Thus, unless a drag penalty is acceptable, such serrations are unlikely to be implemented on high Reynolds number turbomachinery components. Cactus trees [18-19] and palm trees [20-21] are optimized by nature to reduce drag and therefore shear stresses on their trunks. Unfortunately one of the factors in their optimization is variable wind direction which results in a serrated circular trunk cross-section with no net lift force. Chevronshaped protuberances on Sailfish skin [22-23] possibly serve to keep flow attached during maneuvering at high speeds. This results in larger drag and is therefore not beneficial to propulsion applications except where it might serve to reduce separation and thus offset the drag penalty. In these cases, the chevrons would be highly sensitive to relative flow direction and Reynolds number and would only be suited for a particular design.
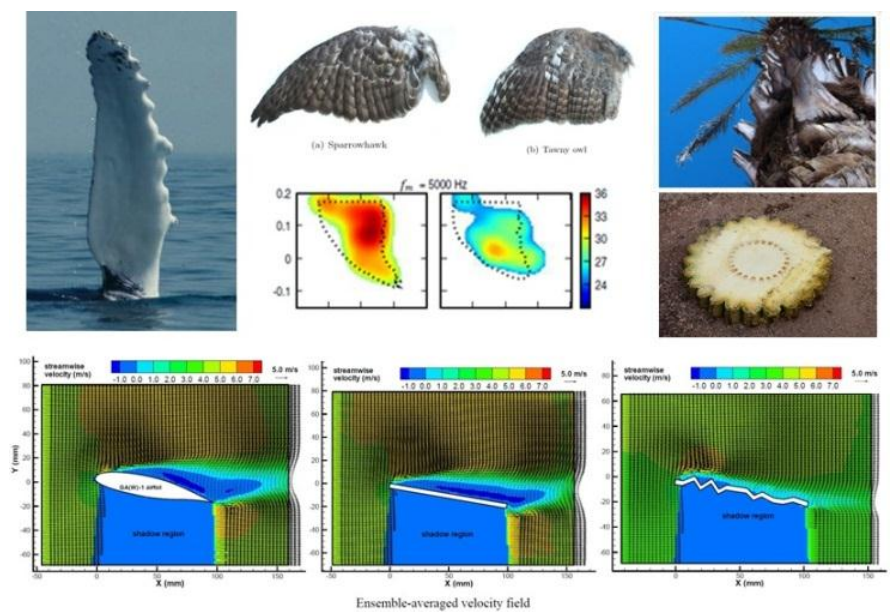

Figure 2. Some of Nature's answers to separation and noise. [8-26]

Figure 2 shows some biological features that have inspired solutions to aerodynamic problems. Owl wings [24] are shown (Figure 2 top center) here as an excellent acoustic damper. It has been observed by several authors that Harbor Seal vibrissae allow the seal to detect slight disturbances in the water upstream of them by pushing the vortices from their whiskers downstream and away from them [25-26]. It was noticed by Hanke et al. [26] that the unsteady forces on the seal vibrissae were reduced by $90 \%$ while the drag was reduced by $40 \%$. This is markedly different from other sinusoidal treatments as noted by Hanke et al. [26] in that most sinusoidal treatments such as the Scruton helix, or sinusoidal leading edges on blades are unable to impact drag in a positive manner while maintaining incidence tolerance or reducing vortex induced vibrations (VIV). It appears that if a similar approach were used on a turbine blade we can achieve a thinning of the wake and a reduction or elimination of separation. The modified nature of the wake indicates that there may be an opportunity for noise reduction. This could depend on the wavelength or amplitude of undulations as well as flow conditions.

In this paper, a seal-whisker-inspired turbine blade is compared to an untreated power turbine blade at multiple incidence angles and for varying geometry of the treated blades. The work presented in this paper is to the authors' knowledge the first investigation of a biomimetic drag reduction and acoustic attenuation concept applied to internal flow in engine realistic conditions.

\section{CONCEPTUAL APPROACH}

The implementation of biomimicry on a turbine blade or a fan blade is very different to that on a low speed wind turbine or even on the wing of an airplane. For example, whale tubercles [8-13] have been shown to improve incidence tolerance on average over a wide range of incidence angles by making the leading edge region more insensitive to incidence. This is accomplished by drawing the flow into valleys and the formation of counter rotating vortical structures. On a turbine blade, due to the high loading, range of incidence angles and large camber,

This material is declared a work of the U.S. Government and is not subject to copyright protection in the United States.

Approved for public release. Distribution is unlimited. 
separation can occur both near the crown region and along the suction side. Separated regions also exit on the pressure side for negative incidence. The wake from these internal flows has an impact on downstream blade rows and must be managed for both performance and acoustic reasons.

Seal Whiskers from elephant and harbor seals as well as whiskers from California sea lions were obtained from the Marine Mammal Center in California to 1. Compare measurements to Hanke et al. [26] based on a wide range of age groups, 2. Determine the universality of features between Harbor and Elephant seals. 3. Perform a sensitivity analysis on the various parameters involved such as pitch of undulations, angle of inclination, free stream turbulence and Reynolds number. Figure 3 shows the whisker samples obtained. These whiskers were analyzed using 3D scans, optical microscope and CT scans. Figure 4 shows images obtained using optical microscope scans that clearly show the undulations on the seal and elephant seal whiskers and parameters used in this work.

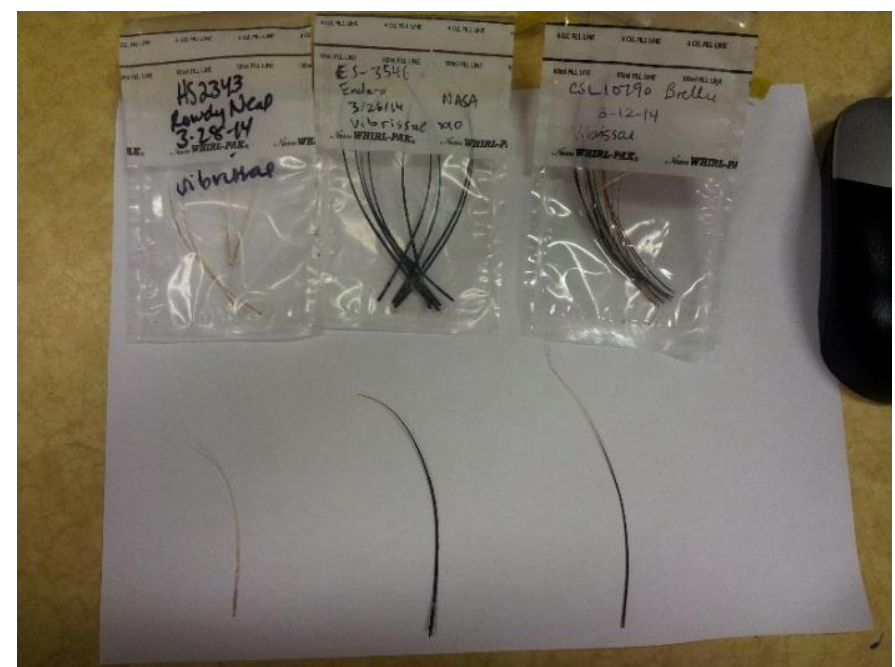

Figure 3. Samples of Pinniped vibrissae obtained from the Marine Mammal Center, California.

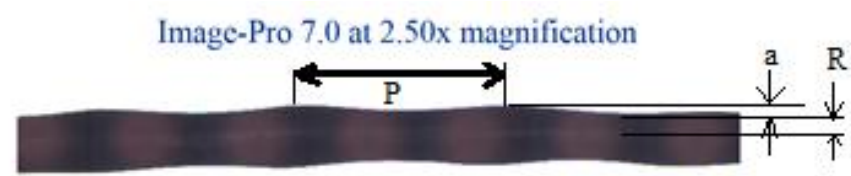

Elephant Seal

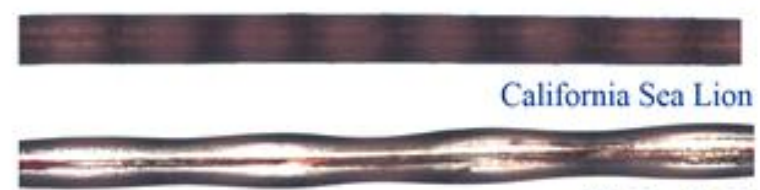

Harbor Seal leading edge undulations match the undulations of the seal vibrissae. Figure 5 (right) shows an untreated airfoil section of a variable speed power turbine (VSPT) blade [1]. The leading edge circle with radius, $\mathrm{R}$, is shown. Figure 5 (left) shows the pressure side of a Seal blade. The VSPT blade was chosen for 2 primary reasons. First, the 'treatment' of this blade was made easy by the fact that the pressure side of a 'treated' blade did not change much from the original VSPT blade. Undulations on the pressure side are undesirable because they cause a loss in power extraction due to force vectors acting along the span of the blade. Assuming that the local pressures do not significantly change this would lead to a loss of power extraction for a turbine or work addition for a fan or compressor blade. Secondly, as a preliminary study, it was desirable to attack troublesome cases that could benefit from significant improvements. The 3D Unsteady RANS code Glenn-HT was used to simulate the baseline Rolls Royce 'incidence tolerant' VSPT blade (airfoil section shown in figure 5 - right [1]) that was tested in NASA Glenn's CW-22 facility at angles of attack of negative incidence, 0 degrees and high positive incidence. This blade showed separation at negative and at high positive incidence angles. The large thickness to chord ratio of the blade provided enough volume for work on the interior of the blade for flow control activities that are beyond the scope of this paper.

The Untreated VSPT airfoil section was used to form a 'treated' Seal blade by sweeping the VSPT airfoil section through sinusoidal profiles of varying pitch and amplitude. Figure 5 shows the parameters of interest for the present study. The pitch, $\mathrm{P}$ and amplitude, $\mathrm{a}$, of the undulations were varied to match the pitch to amplitude ratio and pitch to leading edge radius of the seal vibrissae (see figure 4). Table 1 shows the range of pitches and amplitudes explored in this study. The highlighted cells contain parameters that are the same for the seal treated blades as they are for the seal vibrissa. For example, The Sin1R0P5 blade has the same R/P and a/P as the Seal whisker but the Sin1R1P0 has only the same R/P value.
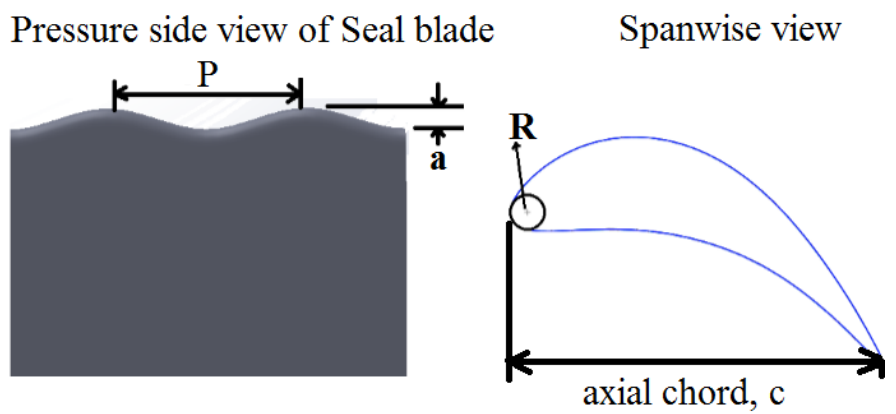

Figure 5. Parameters of undulations for the 'Seal Blade'.

\section{Figure 4. Scans of Pinniped vibrissae using optical microscope showing vibrissae parameters.}

Observations of the seal whiskers prompted the incorporation of undulations for an entire blade such that the

This material is declared a work of the U.S. Government and is not subject to copyright protection in the United States. Approved for public release. Distribution is unlimited. 
Table 1. Parameters of undulations for the VSPT mid-span airfoil section [1].

\begin{tabular}{|l|c|r|r|r|r|}
\hline Parameters & Seal & Sin1R0P5 & Sin1R1P0 & Sin2R0P5 & Sin2R1P0 \\
\hline Reference Radius, R & 0.54 & 0.46 & 0.46 & 0.46 & 0.46 \\
\hline Peak to Peak, P & 1.82 & 1.55 & 1.55 & 3.00 & 3.00 \\
\hline LE amplitude, a & 0.12 & 0.12 & 0.23 & 0.12 & 0.23 \\
\hline ratio R/P & 0.29 & 0.30 & 0.30 & 0.15 & 0.15 \\
\hline ratio a/P & 0.07 & 0.07 & 0.15 & 0.04 & 0.08 \\
\hline
\end{tabular}
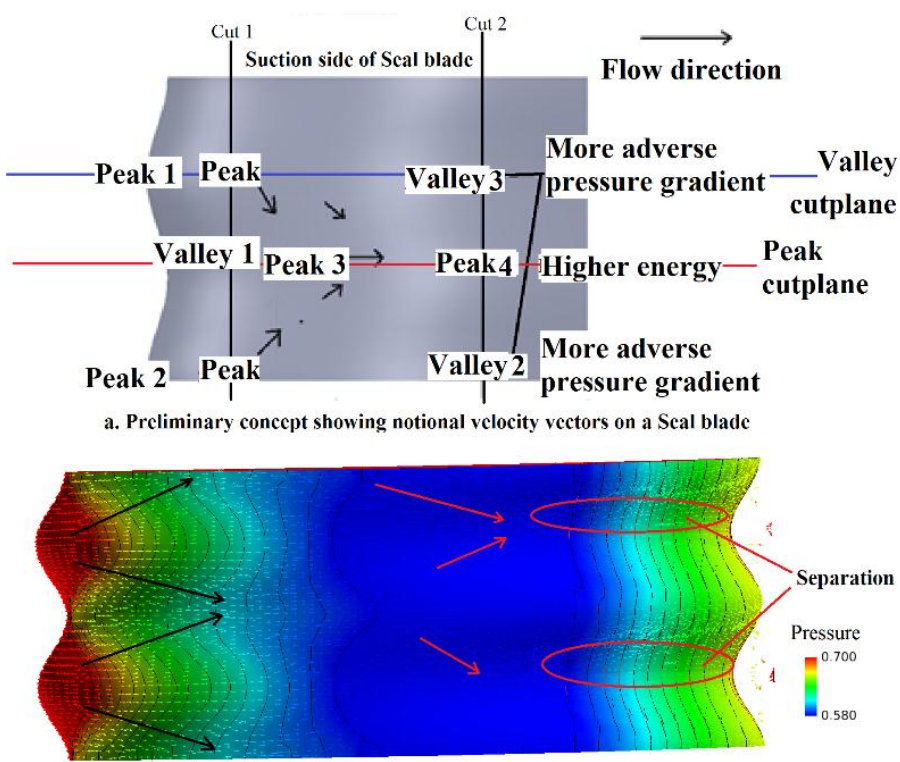

b. Surface pressure map with flow directions based on 3D CFD for Seal blade Sin2R0P5

Figure 6 Seal blade concept showing undulations on suction side and on leading edge - a. Preliminary concept showing benefit of Seal blade, b. Sample CFD Nondimensional pressure map showing velocity vectors.

The seal vibrissae are comprised of elliptical cross sections that are inclined at $15-17^{\circ}$ to the flow direction according to Hanke et al. [26]. Preliminary measurements using optical microscope and CT scans resulted in angles that were significantly smaller than $15-17^{\circ}$, namely in the range of $5-7^{\circ}$. This angle was therefore not included in the present study as it is unclear whether or not the angle is due to the flexibility of the whisker or due to the flexibility of the skin. It was intended to add the inclination in the event that the geometry without the inclination did not show any significant changes from the baseline geometry. This was not necessary in the present study. The pressure side is largely unaffected and does not suffer from undulations that would cause a reduction in lift. This preserves the $2 \mathrm{D}$ airfoil profile for simplified design. Figure 6 shows the logic for treating the blade as described. Figure 6a shows flow approaching Peak 1 encountering the blade first and seeing a spherical surface. The 3D relief accelerates the flow and crown separation if it exists would be pushed further aft. The peak downstream of Peak 1 experiences the lowest pressure of any point along cut 1. A pressure gradient exists between Peak 3 and Peak 1 such that flow downstream of Peak 1 moves toward Peak
3 and continues along the peak that is formed downstream of Peak 3. This is a high momentum stream and is thus less prone to separation. The flow in the adjacent valleys however is lower momentum flow but is energized by the span-wise pressure gradient. This causes a delayed separation or a mitigation of separation. The advantage of this scheme would be that separation or severe adverse pressure gradient regions would be confined to valleys along the trailing edge of the blade. Active flow control can then be used sparingly in these regions. The distortion of the wake would also lead to a modified acoustic spectrum that could lead to noise reduction. For blades with no separation, a thinning of the suction surface boundary layer would occur thus resulting in drag reduction. It is possible using various extrusion methods to create undulations only on the suction side and to tailor the undulations to the type of blade loading (aft, mid, front). The resulting waves on the trailing edge serve to mix the wake in the span-wise direction and thin the wake in the pitch-wise direction. This hypothesis will be tested in future work.

Figure $6 \mathrm{~b}$ shows the surface pressure map on the Seal blade Sin2R0P5. Velocity vectors were plotted near the surface and for the sake of clarity the local flow direction is shown using arrows to validate the initial hypothesis. Near the trailing edge, the circled areas show separation bubbles confined to the trailing edge Valley regions.

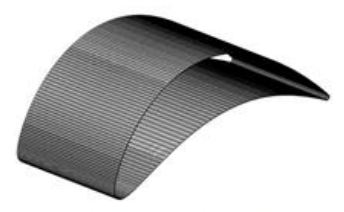

a. Untreated

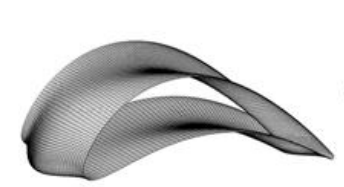

c. $\operatorname{Sin} 1 \mathrm{R} 1 \mathrm{P} 0$

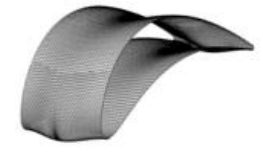

b. Sin1R0P5

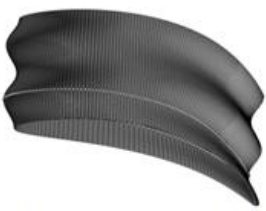

d. $\operatorname{Sin} 2 \mathrm{R} 1 \mathrm{P} 0$
Figure 7. Blades simulated using CFD. a. Untreated, b. Sin1R0P5, c. Sin1R1P0, d. Sin2R0P5. Not shown Sin2R1P0.

\section{COMPUTATIONAL SETUP}

The numerical investigations were conducted using a NASA, in-house, Unsteady Reynolds-Averaged Navier-Stokes code, Glenn-HT [27]. For the work reported in this paper a twoequation model, namely the SST - transition enabled twoequation model [28] is used. The geometry considered is the Rolls Royce Variable Speed Power Turbine Blade Cascade blade [1]. As discussed earlier, the cascade was deemed a suitable case for the initial testing of the concept due to its large thickness to chord ratio, design for power turbine application and due to the existence of separation. The setup of the models will be briefly described below. The cascade geometry cases shown in Table 1

This material is declared a work of the U.S. Government and is not subject to copyright protection in the United States. Approved for public release. Distribution is unlimited. 
were simulated. Surface meshes for 4 of the cases are shown in Figure 7. For these cases, the baseline grid had 7 million grid points per span-wise pitch and was generated as a multi-block grid with 567 blocks per period using GridPro. Figure 8 shows a snapshot of the grid for the Untreated blade. Cases were run with a once-coarsened grid with 1.04 million grid points per period after comparison of results from both grid resolutions for the baseline case.

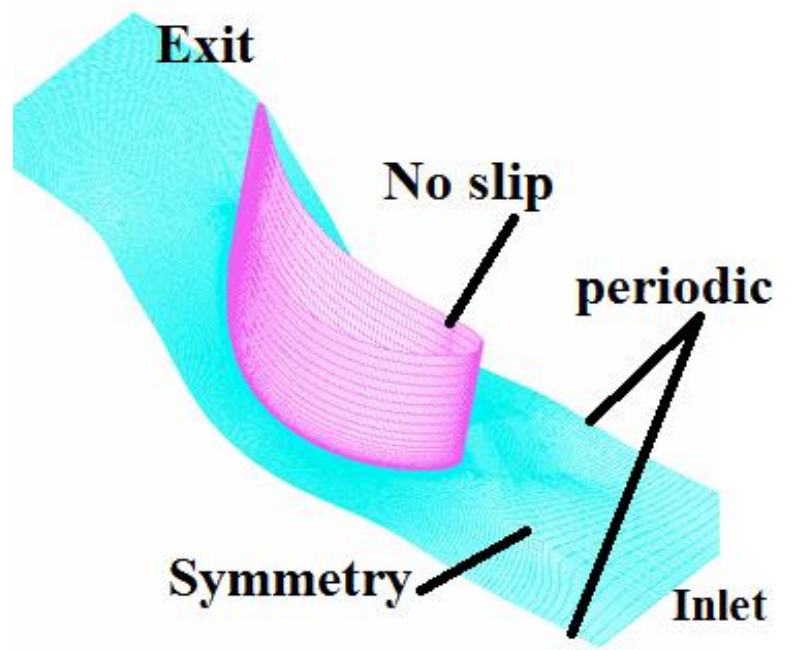

Figure 8. Grid for Untreated blade.

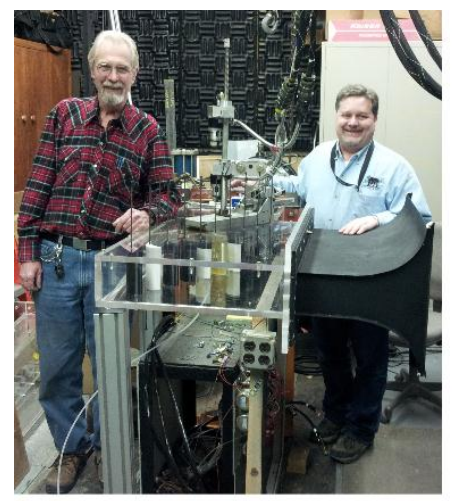

a. SW-2 test facility

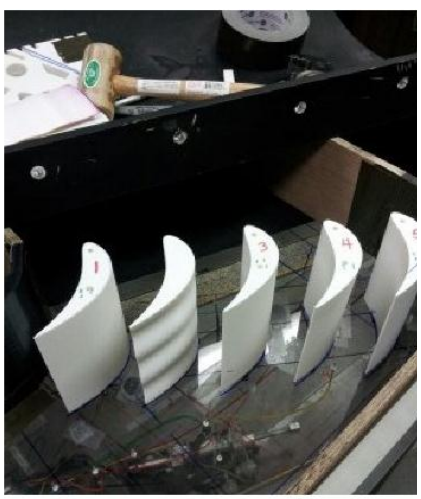

b. Test blades installed in SW-2 wind tunnel
Figure 9. SW-2 wind tunnel facility before (left) and after (right) modifications. [29]

\section{EXPERIMENTAL SETUP}

The SW-2 facility test section shown in figure 9a was redesigned to accommodate testing of biomimetic and flow control test articles. A close up of the test section with blades installed is shown in figure $9 \mathrm{~b}$. The new test section incorporates a modular tunnel and multiple slot locations for wake pressure, hotwire and thermocouple surveys. A modular lid allows optical access for IR or PIV. The inlet was modified to allow a wide range of incidence angles and the test section was modified to allow for blades with high turning angles. A removable ceiling plate allows for rapid exchange of test articles. Hotwire anemometry, total and static pressure and temperature surveys are made possible using a digitally controlled 3-axis actuator system. The tunnel is operated in the Mach 0.1 - Mach 0.7 range. Thurman et al. [29] describe the operation of this facility.

\section{VALIDATION OF CFD}

The CFD was validated in a previous study [1] using the same baseline geometry. Figure 10 shows the pressure distribution around the mid-span airfoil section. Figure 11 shows that the numerical simulations (solid lines) match the data extremely well and more importantly show the separation location at approximately $\mathrm{x} / \mathrm{C}$ of 0.8 . Since this is a feasibility study, the objective of the work presented in this report is not to validate CFD or to obtain accurate flow data but to observe meaningful trends and to lay the foundation for more detailed studies. In particular two major avenues are pursued: 1 . the effect of undulation wavelength and amplitude on performance and 2 . the effect of incidence angle on the Seal blade.

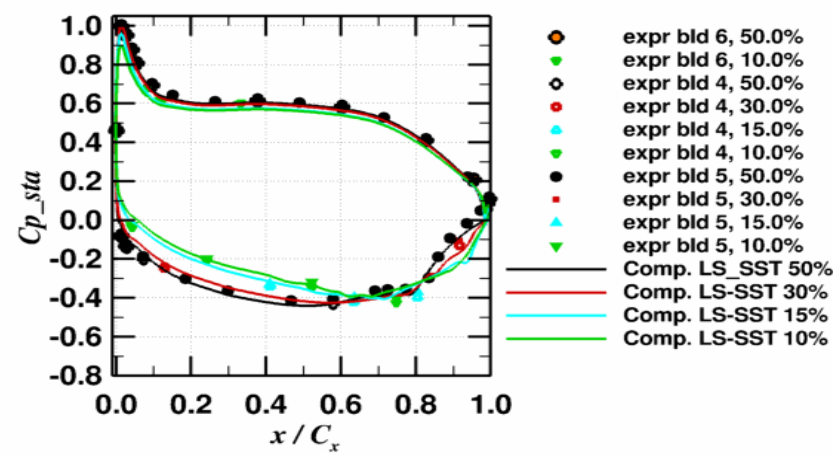

Figure 10. Comparison of CFD to data from NASA CW-22 facility. [1]

\section{RESULTS}

In the figures to follow, blade shapes, velocity distribution over the blade at two locations of peak and valley (except for the plane blade) with their pressure loadings and the total pressure loss distribution at a station $\mathrm{x} / \mathrm{axial}$ chord $=10 \%$ downstream of the trailing edge will be shown. In addition, the average total pressure loss at that location will also be provided. Pressure loss is measured as a loss coefficient, $\mathrm{C}_{\mathrm{p}}=\left(\mathrm{Pt}_{\text {in }}-\mathrm{Pt}\right) /\left(\mathrm{Pt}_{\text {in }}-\mathrm{Ps}_{\text {out }}\right)$.

Here, $\mathrm{Pt}$ is the exit total pressure, $\mathrm{Pt}_{\mathrm{in}}$, is the inlet total pressure and $\mathrm{Ps}_{\text {out }}$, is the exit static pressure measured at $10 \%$ axial chord downstream of the trailing edge of the geometry. All cases shown are for blades that are operated at a Reynolds number of approximately 100,000 based on inlet conditions which makes them transitional. Pressure ratio across the passages is 0.71 .

The results are shown in three sections. In the first section, the untreated VSPT blade is compared to Seal blades that are treated with undulations of varying amplitudes and wavelength. The incidence angle for this comparison was $+5^{\circ}$. For the second section, a comparison between the VSPT untreated geometry and the Seal blade Sin1R0P5 is made for incidence angles of $-37^{\circ}$, $0^{\circ}, 5^{\circ}$ and $10^{\circ}$. The third section briefly describes the potential for acoustic attenuation.

This material is declared a work of the U.S. Government and is not subject to copyright protection in the United States. Approved for public release. Distribution is unlimited. 


\section{Effect of variation of undulation parameters}

Untreated Blade at $5^{\circ}$ incidence

The time-averaged results for the untreated (baseline VSPT) blades are shown first. The domain (not shown) is similar to that shown in figure 8 with a symmetry boundary condition applied in the span-wise direction.

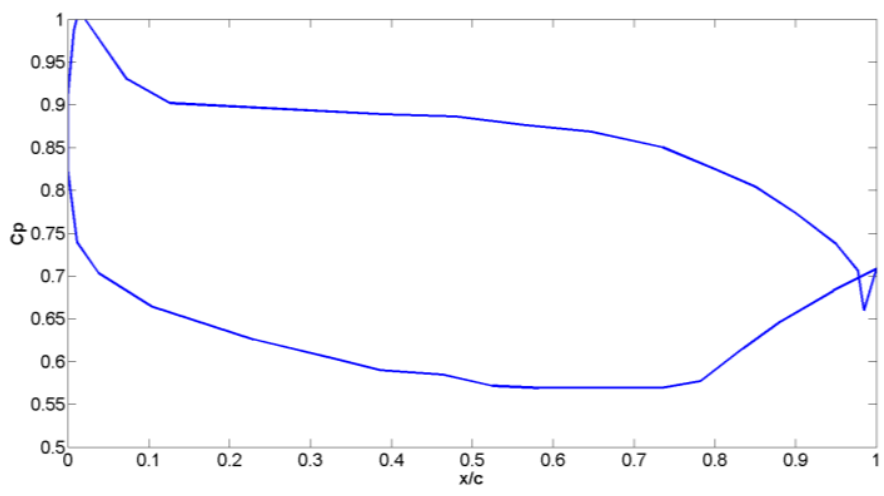

Figure 11. Nondimensional pressure for Untreated blade section at $+5^{\circ}$ incidence angle. Pressure is normalized using inlet total pressure.

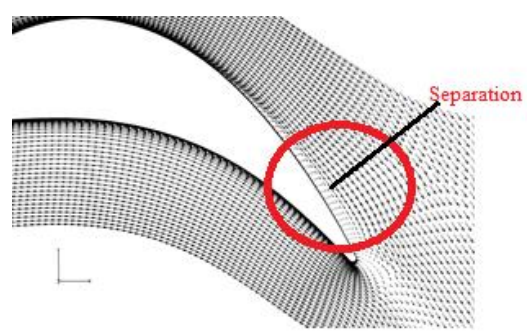

Figure 12. Velocity vectors for Untreated blade showing region of separation on suction side at $+5^{\circ}$ incidence angle.

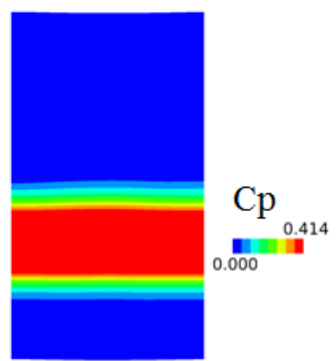

Figure 13. Time-averaged pressure loss coefficient in the wake of the Untreated blade at $x / c=1.1$ and at $+5^{\circ}$ incidence angle.

The nondimensional pressure distribution (normalized by inlet pressure) is shown in figure 11. Separation without reattachment is clearly visible at $\mathrm{x} / \mathrm{c}=0.75$. Here, $\mathrm{x}$ is the axial coordinate direction with $\mathrm{x} / \mathrm{c}=0$ at the leading edge of the Untreated blade. Figure 12 shows the velocity distribution in the passage with the separated zone clearly visible and highlighted by the red circle. The distribution of the total pressure loss at an axial location $\mathrm{x} / \mathrm{c}=1.1$ is shown in Figure 13. The distribution is spanwise uniform with the steady simulation as it should be. The average loss coefficient at the plane downstream of the trailing edge was computed to be $C_{p}=0.12$. This value needs to be reduced by the modifications to the blade.

\section{$\underline{\text { Seal Blades at } 5^{\circ} \text { incidence }}$}

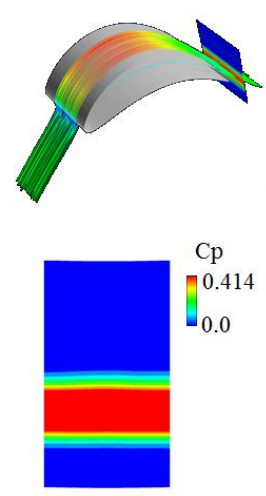

a. Untreated
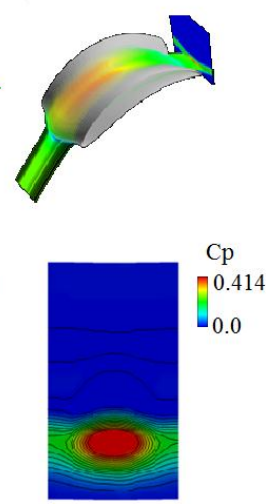

b. Sin1R0P5
Figure 14. Bottom - pressure loss coefficient for a. Untreated blade and $b$. Sin1R0P5 Seal blade at $+5^{\circ}$ incidence angle. Top - Relative location of planes at $\mathrm{x} / \mathrm{c}=\mathbf{1 . 1}$.

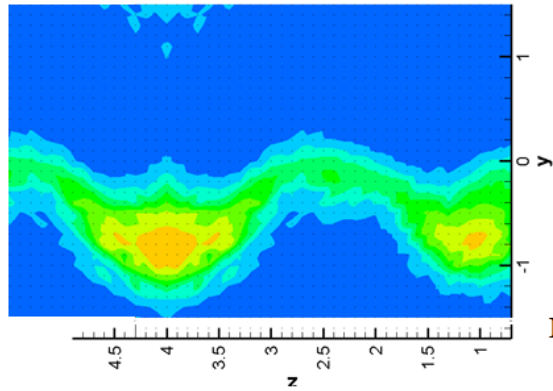

a. wind tunnel pressure surveys

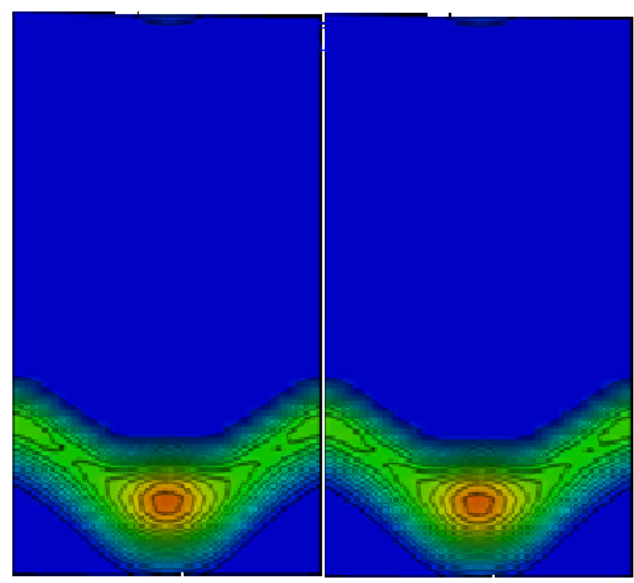

b. CFD

Figure 15. Static pressure in the wake of Sin1R0P5 Seal blade obtained from a. Wind tunnel total pressure survey of the wake at $x / c=1.1$ and $b$. CFD simulation at $+5^{\circ}$ incidence angle

This material is declared a work of the U.S. Government and is not subject to copyright protection in the United States. Approved for public release. Distribution is unlimited. 


\section{Seal Blades}

Figure 14 (bottom) shows a comparison of the pressure loss coefficient in the wake for the baseline blade (Figure 14a) and for the Seal blade Sin1R0P5 (Figure 14b) from the simulations. Figure 14 (top) shows the location of the planes at which the wake pressure contours are compared and pressure loss coefficient is averaged. Note the marked shrinking of the red high loss region in the wake for the Sin1R0P5 case and the characteristic wavy wake profile.

Figure 15a shows the results of a wind tunnel pitot survey at the same relative location as the CFD downstream of the Sin1R0P5 blade. The shape and extent of the wake is well captured by the CFD as can be seen from Figure 15b. Figure 16 shows the pressure coefficient at two spanwise locations for the Seal blades. The two locations are labelled as "Peak" and "Valley" and correspond to the red and blue cut planes respectively shown in Figure 6a. These are span-wise cuts across the blade that pass through Peak 3 and Valley 3 respectively. These Peak and Valley locations are referred to in the remainder of this paper. Figure 16a shows the pressure distribution at the Valley location for all the Seal blades along with the Untreated blade. Figure 16b shows the Nondimensional pressure distributions at the Peak location for all blades at $+5^{\circ}$ incidence angle. The green markings below the abscissa indicate regions where the Seal blade improves on the loading of the Untreated blade and the red regions show detrimental loading changes. The trailing edge separation at approximately $\mathrm{x} / \mathrm{c}=75$ is clearly visible on the Untreated blade thus reducing the loading of the blade. Along the peak, the separation is almost eliminated and pressure distribution on the suction side is quite constant. Blade loading is shifted from the aft region to the front region which would reduce losses in a rotating blade as more work is extracted before loss mechanisms can kick in. In the Valley region (Figure 16a) a marked improvement in the blade loading is noticed in the aft $20 \%$ of the blade where the separated region of the Untreated blade is 'filled in'. The wake loss contours at $10 \%$ chord downstream of the blade is most interesting where the low total pressure regions are concentrated behind the valley. The average total pressure loss coefficient for this case was computed to be $\mathrm{C}_{\mathrm{p}}=0.069$ which is approximately 50 percent lower than the Untreated blade. This is very promising. The particular conclusion that the treatment leads to boundary layer reattachment and a reduction of losses has been repeatedly verified. The pressure coefficient plots at the valley and peak locations show that the lift on the airfoil is significantly increased for the Peak location while not changing much for the Valley location.
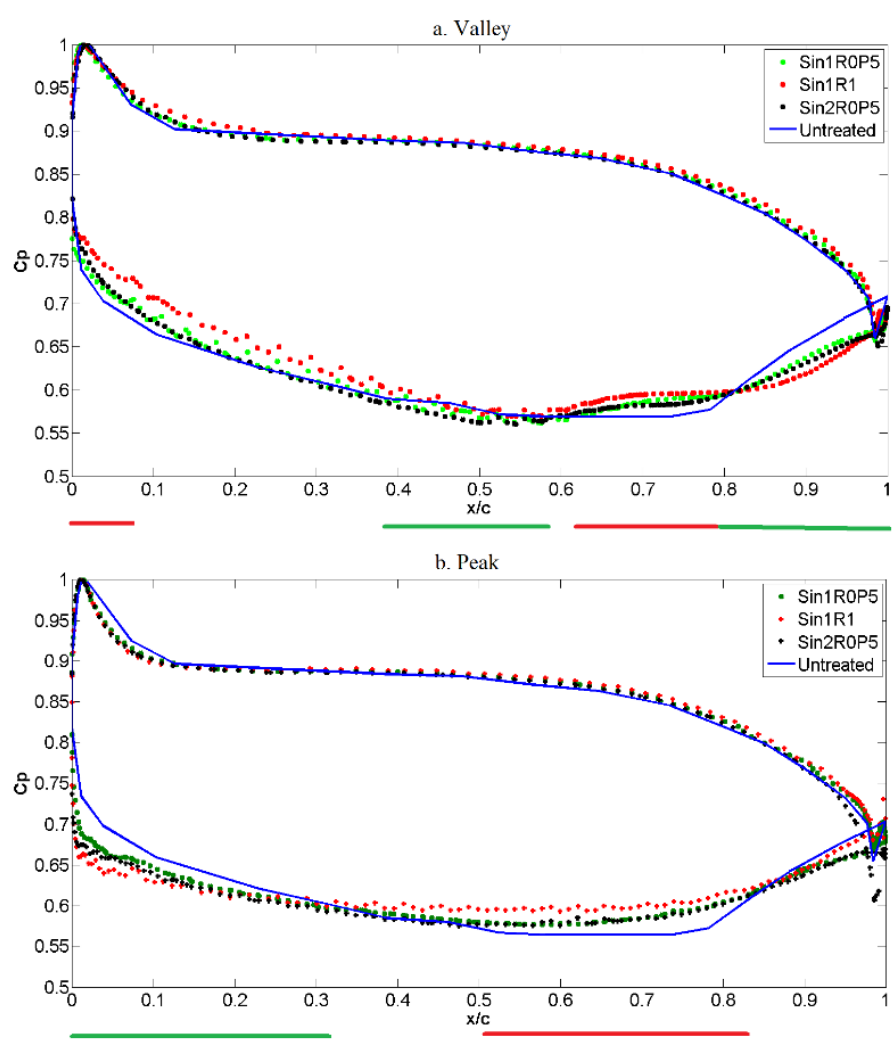

$$
\begin{aligned}
& \text { Untreated is superior } \\
& \text { Seal blade is superior }
\end{aligned}
$$

Figure 16. Nondimensional pressure at a. Valley and b. Peak for Seal blades and Untreated blade section at $+5^{\circ}$ incidence angle. Pressure is normalized using inlet total pressure.

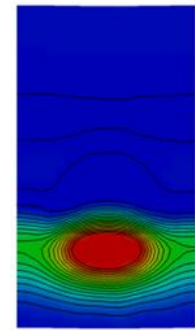

a. Sin1R0P5

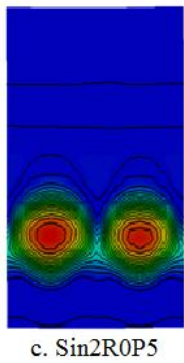

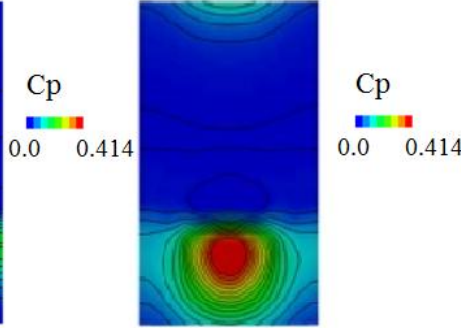

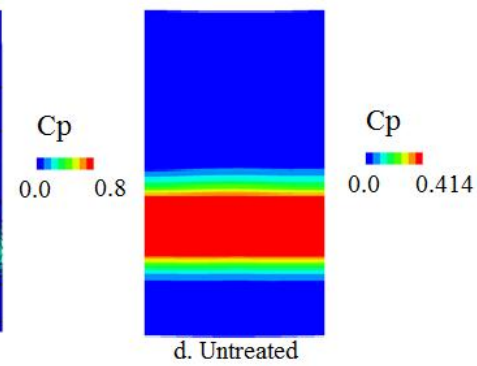

b. $\operatorname{Sin} 1 \mathrm{R} 1 \mathrm{P} 0$

Figure 17. Wake pressure loss coefficients for Seal blades compared to Untreated blade.

This material is declared a work of the U.S. Government and is not subject to copyright protection in the United States. Approved for public release. Distribution is unlimited. 


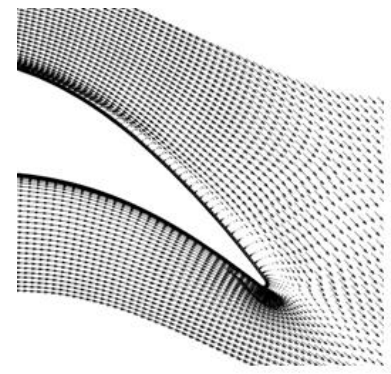

a. Valley

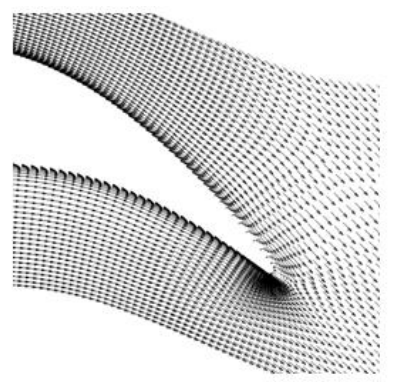

b. Peak

Figure 18. Velocity vectors at a. Valley and b. Peak for Sin1R0P5 blade.

Figure 17 shows the $\mathrm{x} / \mathrm{c}=1.1$ plane with contours of pressure loss coefficient for the Seal blades and the Untreated blade. For all cases it is evident that the loss core is limited to the Valley region. Confirmation of this phenomenon is seen in Figure 18 that shows velocity vectors for the Sin1R0P5 blade. An unsteady separation exists in the Valley location while the Peak location shows no tendency to separate. Similar results were observed for the other Seal blade cases and are omitted for brevity. Hotwire surveys were conducted in the wake of the Untreated blade and the Sin1R0P5 blade. Results showed a reduction in turbulence intensity in the wake by up to $4.5 \%$. This is probably due to the elimination or reduction of separation.

For the Sin1R1P0 blade the level of integrated total pressure loss over the plane at $\mathrm{x} / \mathrm{c}=1.1$ was computed to be $\mathrm{C}_{\mathrm{p}}=0.066$, similar to the Sin1R0P5 case. The loss coefficients for the Sin2R0P5 and Sin2R1P0 blades were computed to be 0.066 and 0.085 respectively. These loss coefficients were obtained by integrating loss over the planes shown in Figure 17.

\section{Effect of incidence angle}

The same geometries were tested at $0^{\circ}, 10^{\circ}$ and $-37^{\circ}$ in addition to the $5^{\circ}$ cases that were discussed in the previous section incidence to check whether performance had been compromised at other incidence angles. The Seal blade showed improvements over the untreated blades over all incidence angles. Representative results for a limited number of cases are shown here for brevity. Figure 19a shows velocity vectors for the Untreated blade at $10^{\circ}$ incidence angle and figure $19 \mathrm{~b}$ shows the nondimensional pressure distribution at mid-span. Figure 20 shows pressure distribution at Valley and Peak for the Sin1R0P5 blade at $10^{\circ}$ incidence angle. Here, at the peak location, separation is again seen to be removed and the wake structure is similar to that at lower incidence angles.

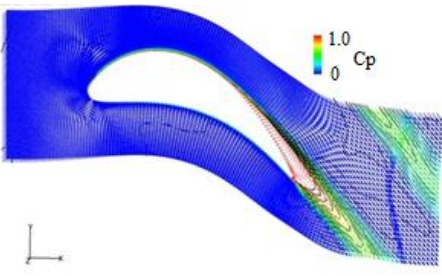

a. Velocity vectors

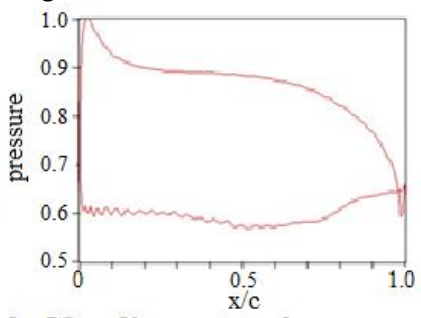

b. Nondimensional pressure
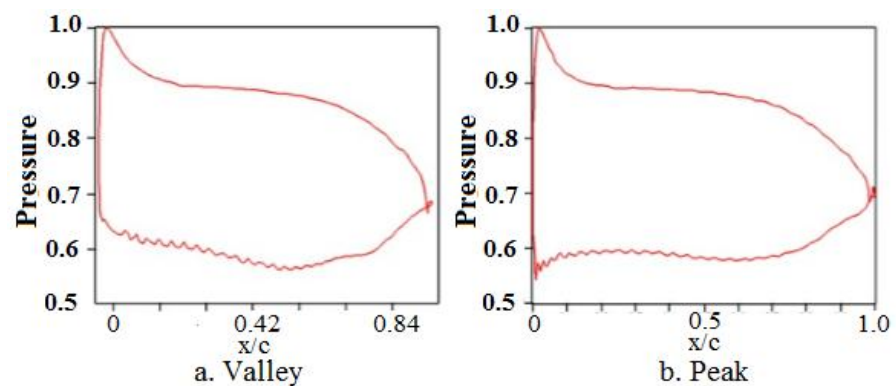

Figure 20. Nondimensional pressure profiles at a. Valley and b. Peak for Sin1R0P5 at $10^{\circ}$ incidence angle.

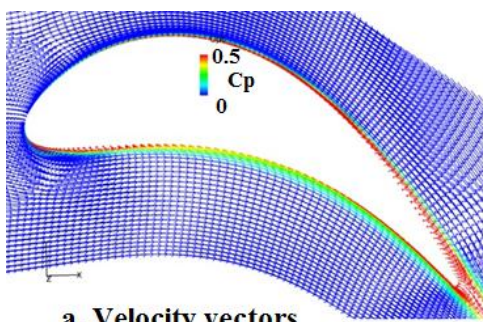

a. Velocity vectors

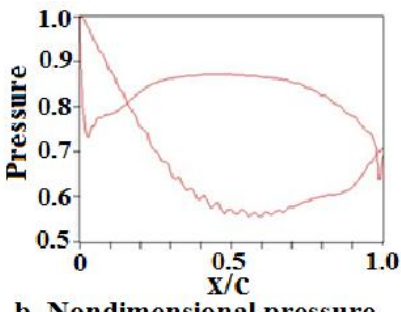

b. Nondimensional pressure
Figure 21. Untreated blade at $-37^{\circ}$ incidence angle.
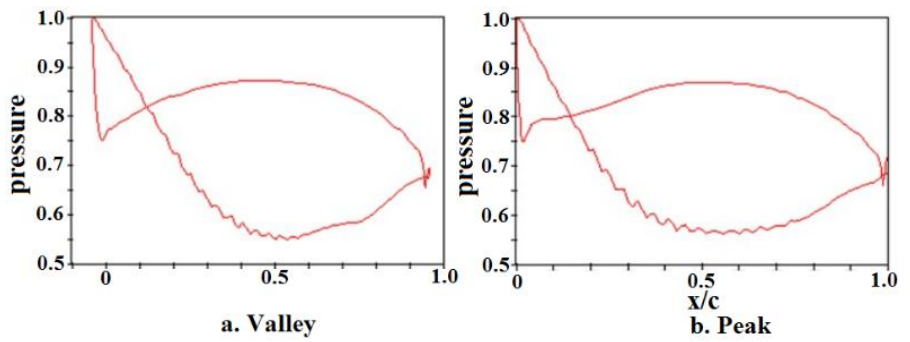

Figure 22. Nondimensional pressure profiles at a. Valley and b. Peak for Sin1R0P5 blade at $-37^{\circ}$ incidence angle.

Figure 21a shows velocity vectors for the Untreated blade at $-37^{\circ}$ incidence angle and figure $21 \mathrm{~b}$ shows the nondimensional pressure distribution at mid-span. Figure 22 shows nondimensional pressure at Peak and Valley locations for the Sin1R0P5 blade. An interesting result was noted at the negative incidence angle. While the untreated blade showed separation on the pressure side and on the suction side at high negative incidence, the Valley location of the Seal blades did not show separation on the pressure side while the Peak location showed no separation on the suction side. This is again a hint that optimization of the undulations along the chord could be beneficial to the overall performance of the blade. For example, the undulation amplitude could be reduced as the flow progresses toward the trailing edge. Alternatively, undulation sweep could be introduced along the trailing edge alone or along the entire blade if endwall flows are considered to take into account radial migration and secondary flow. A summary of results from the cases that were investigated is shown in the summary section to follow.

\section{Figure 19. Untreated blade at $10^{\circ}$ incidence angle.}

This material is declared a work of the U.S. Government and is not subject to copyright protection in the United States. Approved for public release. Distribution is unlimited. 


\section{Acoustic Attenuation}

Hotwire surveys in the wake of the Sin1R0P5 blade showed a reduction in broadband frequency content and a reduction in turbulence intensity. The effect of trailing edge waviness is not explored here and will be addressed in future publications.

\section{SUMMARY OF RESULTS}

Figure 23 shows a plot of total pressure loss coefficient that is an indication of drag for a wide range of incidence angles. The blue line is the Rolls Royce VSPT Power Turbine blade that was optimized by Rolls Royce for the range of incidences shown. The red line shows the loss associated with the Seal Blade. The Seal Blade is largely insensitive to incidence angles and Figure 24 shows averaged wake loss coefficients from the unsteady simulations of the multiple Seal Blade variations that were studied using 3D unsteady Computational Fluid Dynamics (CFD). Figure 24 shows that decreased pitch of the undulations causes a decrease in benefit from the undulations. For a given pitch, it appears that a larger undulation amplitude has lower loss (refer to Table 1 for pitch and amplitude specifications for each case.)

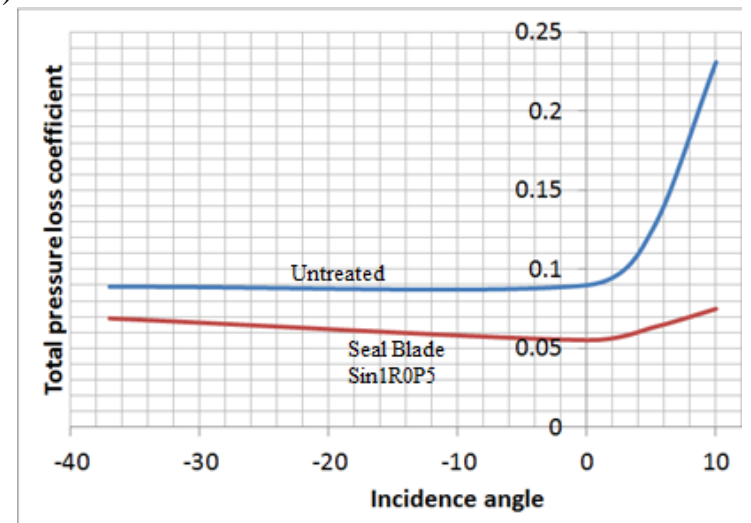

Figure 23. Incidence tolerance - Comparison between baseline VSPT blade and S1R0P5 over a wide range of incidence angles $\left(-37^{\circ}, 0^{\circ}, 5^{\circ}\right.$ and $\left.10^{\circ}\right)$.

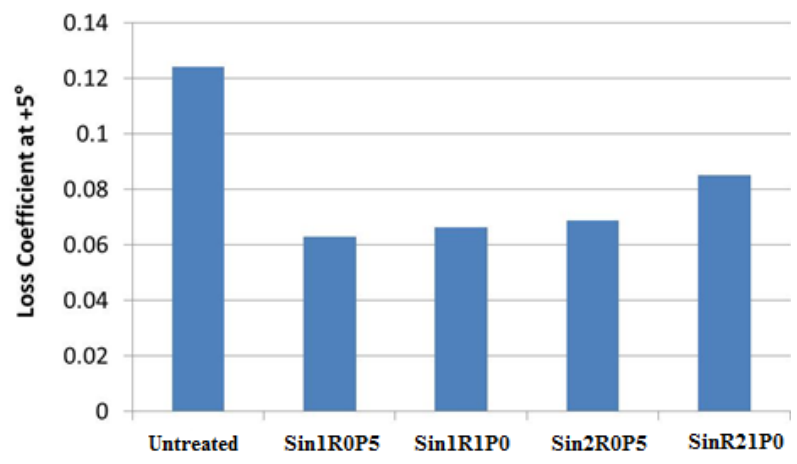

Figure 24. Performance improvements from Seal blades average pressure loss coefficient in the wake for seal blades compared to VSPT blade at $5^{\circ}$ incidence angle.

\section{CONCLUSION}

The feasibility of a Seal Whisker treated turbine blade has been demonstrated that could lead to reductions in drag of up to $50 \%$. It was observed that a smaller undulation pitch has larger benefit on performance and that the amplitude of the undulation does not have a significant effect. Blades treated with the Seal Vibrissalike undulations were shown to be insensitive to incidence tolerance. In addition, owing to the modified structure of the wake both in an average sense and in terms of frequency content, acoustic benefits are a possibility but were not explored in this work. Further work should look at optimization of Seal whisker parameters and include the effect of rotation and stator-rotor interaction. More can be achieved by applying to fan noise reduction, compressor stall control, airframe drag and noise reduction, landing gear drag reduction and structural integrity. Similar gains may be achieved for struts, probes, road signs, electrical cables, oil rig riser legs, wind turbine supports, marine transport, trucks and numerous other applications. Due to the separated nature of the flows considered, the computations tend to be unsteady.

\section{ACKNOWLEDGMENTS}

The authors would like to thank the National Aeronautics Research Institute for funding this study.

\section{REFERENCE}

1. Welch, G. E., McVetta, A. B., Stevens, Mark A., Howard, S. A., Giel, P. W., Ameri, A. A., To, W. M, Skoch, G. J., and Thurman, D. R., "Variable-Speed Power Turbine Research at Glenn Research Center," Presented at the American Helicopter Society $68^{\text {th }}$ Annual Forum, Fort Worth, Texas. May 1-3, 2012.

2. Johnson, W., "NDARC, NASA Design and Analysis of Rotorcraft," NASA TP 2009-215402, December 2009.

3. Hodson, H.P. and Howell, R. J., "Bladerow Interactions, Transition, and High-Lift Aerofoils in Low-Pressure Turbines" Annual Rev. Fluid Mech. 2005. 37:71-98.

4. Bechert, D.W., Bruse M., Hage W., Van Der Hoeven J. G. T. and Hoppe G., "Experiments On Drag-Reducing Surfaces And Their Optimization With An Adjustable Geometry", J. Fluid Mech. (1997), Vol. 338, pp. 59-87, Copyright 1997 Cambridge University Press.

5. Bechert, D. W., Hoppe, G. and Reif, W.-E., "On The Drag Reduction Of The Shark Skin," AIAA, Paper 850546, 1985.

6. García-Mayoral and R., Jiménez, J., "Drag Reduction by Riblets", Phil. Trans. R. Soc. A: 2011369 14121427; DOI: 10.1098/rsta.2010.0359.Published 7 March 2011.

7. Halasz, C., "Advanced Trailing Edge Blowing Concepts for Fan Noise Control: Experimental Validation," MS Thesis, Virginia Polytechnic Institute, 20 June 2005, Blacksburg, VA.

This material is declared a work of the U.S. Government and is not subject to copyright protection in the United States. Approved for public release. Distribution is unlimited. 
8. Miklosovic, D. S., Murray, M. M., Howle, L. E. and Fish, F. E. "Leading-Edge Tubercles Delay Stall On Humpback Whale (Megaptera Novaeangliae) Flippers." Physics of Fluids, Vol.16, March 2004.

9. Fish, F. E., Weber, P. W., Murray M. M., and Howle, L. E., "The Tubercles on Humpback Whales' Flippers: Application of Bio-Inspired Technology", Integrative and Comparative Biology, volume 51, number 1, pp. 203-213, doi:10.1093/icb/icr016.

10. van Nierop, E. A., Alben, S., and Brenner. M. P., "How Bumps On Whale Flippers Delay Stall: An Aerodynamic Model." Physical Review Letters, 100(5):054502, February 2008.

11. Weber, P. W., Howle, L. E., Murray, M. M., and Miklosovic. D. S., "Computational Evaluation Of The Performance Of Lifting Surfaces With Leading-Edge Protuberances." Journal of Aircraft, 48(2):591\{600, 2011.

12. Hansen, K. L., Kelso, R. M. and Dally, B. B. "Performance Variations of Leading-Edge Tubercles for Distinct Airfoil Profiles," Journal of Aircraft, 49(1):185-194, 2011.

13. Johari, H., Henoch, C., Custodio, D., and Levshin A., "Effects of Leading-Edge Protuberances on Airfoil Performance," AIAA Journal, 45(11):2634-2642, 2007.

14. Miklosovic, D. S., Murray, M. M. and Howle, L. E., "Experimental Evaluation of Sinusoidal Leading Edges," Journal of aircraft, 44(4):1404-1408, 2007.

15. Okamoto, M., Yasuda, K., and Azuma, A., "Aerodynamic Characteristics of the Wings and Body of a Dragonfly." Journal of Experimental Biology. Vol. 199, 1996, pp. 281- 294.

16. Kessel, A. B., "Aerodynamic Characteristics of Dragonfly Wing Sections Compared With Technical Aerofoils," The Journal of Experimental Biology 203, 3125-3135 (2000) 3125, Printed in Great Britain (C) The Company of Biologists Limited 2000, JEB2811.

17. Masatoshi Tamai, Zhijian Wang, Ganesh Rajagopalan, Hui Hu, "Aerodynamic Performance of a Corrugated Dragonfly Airfoil Compared with Smooth Airfoils at Low Reynolds Numbers", 45th AIAA Aerospace Sciences Meeting and Exhibit, Jan 8 - 11, 2007, Reno, Nevada AIAA-2007-0483.

18. Babu, P., and Mahesh, K., " Aerodynamic Loads on Cactus-shaped Cylinders at Low Reynolds Numbers", Phys. Fluids 20, 035112 (2008); doi: 10.1063/1.2887982.

19. Talley, S., Iaccarino, G., Mungal, G. and Mansour, N., "An Experimental and Computational Investigation of Flow Past Cacti," Annual Research Briefs, Center for Turbulence Research, NASA Ames/Stanford University, 2001, pp. 51-63.

20. Mayer, H. and Schindler, D., "Wind Effects on Trees," Proceedings of the 2nd International Conference Albert-Ludwigs-University of Freiburg, Germany, 1316 October 2009.
21. Halle, J., "Aerodynamic Features of the Tree", Journal of Arboriculture 16(9); September 1990.

22. Chen, Y., Chew, Y. T. and Khoo B. C., "Turbulent Flow Manipulation by Passive Devices", Proceedings of the 13th Asian Congress of Fluid Mechanics, 17-21 December 2010, Dhaka, Bangladesh.

23. Woong S., Chulkyu K., Sangho C., Woo-Pyung J, and Haecheon C., "Does the Sailfish Skin Reduce the Skin Friction Like the Shark Skin?" Phys. Fluids 20, 101510 (2008); doi: 10.1063/1.3005861.

24. Geyer, T., Sarradj, E. and Fritzsche, C., "Silent Owl Flight: Experiments in the Aeroacoustic Wind Tunnel," NAG/DAGA 2009, Rotterdam.

25. Dehnhardt, G., Mauck, B., Hanke, W. and Bleckmann, H., "Hydrodynamic trail following in harbor seals (Phoca vitulina)," Science 293, 102-104, 2001.

26. Hanke, W., Witte, M., Miersch, L., Brede, M., Oeffner, J., Michael, M., Hanke, F., Leder, A., and Dehnhardt, G., "Harbor seal vibrissa morphology suppresses vortex-induced vibrations," The Journal of Experimental Biology 213, 2665-2672 (C) 2010. Published by The Company of Biologists Ltd., doi:10.1242/jeb.043216.

27. Steinthorsson, E.; Liou, M. S.; and Povinelli, L. A., "Development of an Explicit Multiblock/Multigrid Flow Solver for Viscous Flows in Complex Geometries," AIAA-93-2380 (NASA TM-106356), 1993.

28. Langtry, R. B. and Sjolander, S. A., "Prediction of Transition for Attached and Separated Shear Layers in Turbomachinery," AIAA 2002-3641, 2002.

29. Thurman, D., Poinsatte, P., Heidmann, J., "Heat Transfer Measurements for a Film Cooled Turbine Vane Cascade," Proceedings of ASME Turbo Expo 2008: Power for Land, Sea and Air GT2008, June 9-13, 2008, Berlin, Germany, GT2008-50651

This material is declared a work of the U.S. Government and is not subject to copyright protection in the United States. Approved for public release. Distribution is unlimited. 